\title{
Global Marketing Management - A Critical Study
}

\author{
${ }^{1}$ Dr. K.V.S.N Jawahar Babu, ${ }^{2}$ B. Muniraja Sekhar \\ ${ }^{I}$ Professor, Department of Management Studies, KMM Institute of Technology\& Science, Tirupati. \\ ${ }^{2}$ Research Scholar P.HD in Management, S.V.University College of Commerce \& Management and Computer \\ Science, S.V.University, Tirupat
}

\begin{abstract}
In the process of devising global marketing programmers, corporate management requires informational basis, i.e. appropriate marketing studies covering specific issues and opportunities in global operations. Overviews of market conditions and relationships, global product market acceptance tests, regional performance maps, efficiency assessment of individual global marketing mix instruments etc. greatly facilitate devising appropriate global marketing programmers.
\end{abstract}

\section{History}

The term 'globalization' has acquired considerable emotive force. Some view it as a beneficial process - a key to future world economic development-and also inevitable and irreversible. Others regard it with hostility, even fear, believing that it increases inequality within and between nations, threatens employment and living standards, and thwarts social progress

Global marketing is expansive, extensive, and complex. It can be seen as both a business strategy and an operation, as a force for good and/or as the 'new imperialism'. It can be embodied in companies or perceived as a phenomenon (e.g. business globalization, the internet, etc.). One view of global marketing is as a giant supply chain management system or an added value system. Global giants such as Toyota (www.toyota.com), VW (www.vw.com) and DaimlerChrysler (www.daimlerchrysler.com) source their raw materials, semiprocessed and processed materials, finance and human inputs from all over the world and deliver the results of the combination of these, i.e. vehicles, to numerous market segments, adding value as they do so. Defining terms in the global marketing arena are a complex issue. Marketing across political and cultural boundaries raises many questions, problems, and juxtapositions, rendering precise dentitions difficult. Typical issues centre on the standardization-adaptation argument; locus of control - central or devolved; and when exactly a multinational corporation focuses becomes a global one. How does global marketing differ from domestic and international marketing? While there are no universal dentitions, the following are those that we suggest for use throughout this text.

In the 1970s the market segmentation argument was framed as standardization versus adaptation. In the 1980 s it was globalization versus localization and in the 1990s it was global integration versus local responsiveness. The fundamental question was whether the global homogenization of consumer tastes allowed global standardization of the marketing mix. The Internet revolution of the 1990s with its unprecedented global reach added a new twist to the old debate.

\section{Advantages of Global Marketing:}

The advent of new technologies (e.g. the internet and the World Wide Web, mobile devices, digital TV) has opened up business and marketing opportunities in the development of innovative products and services, and the creation of new values to consumers. For instance, conventional marketing and targeting techniques allow an organization to reach hundreds, thousands, or even tens of thousands of potential customers. But with a personal computer and a modem the organization can reach a community of millions at a fraction of the cost. By 2012, eMarketer (www.emarketer.com) projects that over 1.7 billion people worldwide (24.5\%) will access the internet at least once per month. Nearly $50 \%$ of the world's internet population will live in the Asia Pacific region. China has overtaken the USA as the most populous internet nation in the world and the Asia Pacific region will top 500 million internet users. The share of the world's internet users in Europe and North America will fall, though absolute numbers will continue to rise in both regions, as the share of users in Latin America and the Asia Pacific region both grow.

The Netherlands and the Scandinavian countries lead the world in terms of internet penetration, and reached something of a saturation point around $80 \%$ of the population in 2007. Countries such as China, Russia, India, Brazil, and Mexico are relatively immature internet markets and will be the primary drivers for worldwide internet user growth over the next five years. Of growing significance is digital TV, the take-up rate for which 
has exceeded internet usage for the first time in the UK, and other internet-enabled mobile devices such as mobile phones, PC notebooks, and palmtops. More than 8 million people worldwide today have access to television delivered by internet protocol (IPTV) services. IPTV will be used in 38.4 million homes worldwide by 2012 (source: www.informatm.com).

It is estimated that IPTV subscriptions and video-on-demand would generate an estimated US\$14.7 billion in worldwide revenue by 2012, up from US\$1.5 billion in 2006 . That revenue will come from a mere $3.1 \%$ of the world's TV households. More importantly, IPTV has become a major source of internet television advertising for companies seeking to reach customers globally. The revenue for this form of advertising will hit US $\$ 10$ billion worldwide by 2011 , which would equal $18 \%$ of all internet advertising spending, which is forecast at US\$57 billion. The size of the online market is impressive, but size alone is merely the beginning of its attraction for the commercial sector. New technologies can provide a competitive edge because they give businesses a leverage over its time and investment, allow them to target prospective consumers easily, and level the playing fi eld between them and their competitors, no matter how large or well financed. The rapid adoption of these technologies as a commercial medium has led to businesses experimenting with innovative ways of marketing in the electronic environment.

As a commercial medium, new technologies offer opportunities as a powerful delivery channel, a medium for marketing communications, and a market in and of themselves. Those opportunities are associated with the interactive nature of the medium. First, there is significant potential to reduce distribution costs. This can be seen in the cases of publishing, information services, and software. Organizations are able to target customers directly, thus eliminating some of the marketing costs and constraints imposed by conventional methods such as terrestrial television. This may also make distribution more efficient due to reduced overhead costs resulting from uniformity, automation, and integration of management processes. Secondly, online businesses are able to transfer more of the selling function to the customer, through online ordering and the use of e-commerce.

This potential for greater customer interaction facilitates relationship marketing and customer support to a greater degree than has been possible with traditional media. This has provided unprecedented opportunities to customize communications precisely to individual customers, allowing them to request as much or as little information as they wish, when they wish, and how they wish. Finally, the new technologies also bring operational benefits, especially for industrial suppliers, which include reduced errors, time, and overhead costs in information processing; reduced costs to suppliers by electronically accessing online databases of bid opportunities, online abilities to submit bids, and online review of awards.

\section{Benefits of Global Marketing}

- When large market segments can be identified, economies of scale in production and marketing can be important competitive advantages for global companies.

- Transfer of experience and know-how across countries through improved coordination and integration of marketing activities.

- Marketing globally also ensures that marketers have access to the toughest customers.

- Diversity of markets served carries with it additional financial benefits.

- Firms that market globally are able to take advantage of changing financial circumstances.

\section{Planning for Global Markets}

- Planning is the job of making things happens that might not otherwise occur.

- Planning allows for rapid growth of the international function, changing markets, increasing competition, and the turbulent challenges of different national markets.

- Planning relates to the formulation of goals and methods of accomplishing them, so it is both a process and philosophy.

- Corporate planning

- $\quad$ Strategic planning

- Tactical planning

- Successful planning is evaluating company objectives, including management's commitment and philosophical orientation to international business.

\section{The Planning Process}

- Phase 1: Preliminary Analysis and Screening - Matching Company and Country Needs.

- Phase 2: Adapting the Marketing Mix to Target Markets.

- Phase 3: Developing the Marketing Plan

- Phase 4: Implementation and Control 


\section{International Planning Process}

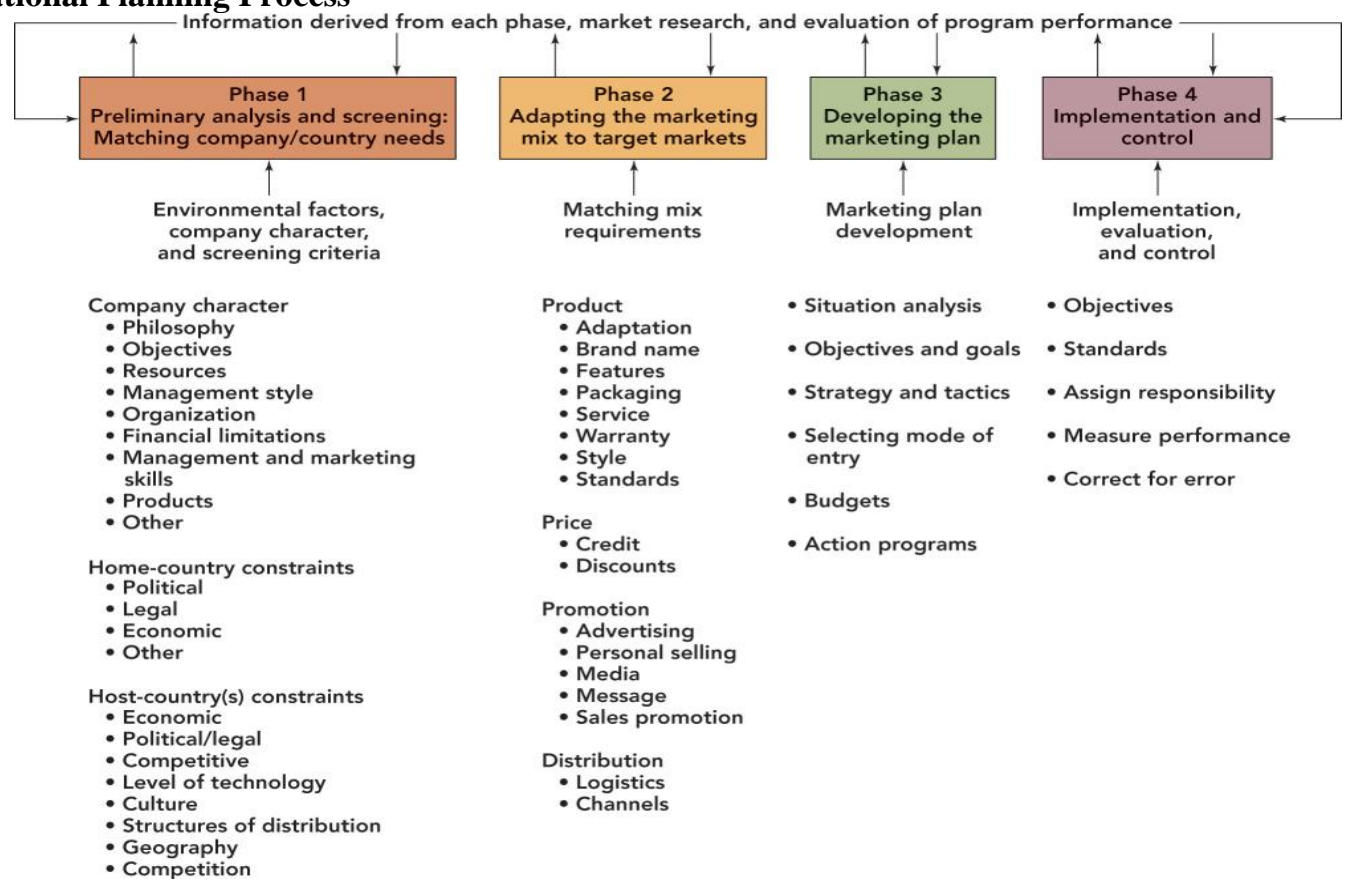

\section{Alternative Market-Entry Strategies}

- An entry strategy into the international market should reflect on analysis of market characteristics such as:

- Potential sales

- Strategic importance

- $\quad$ Strengths of local resources

- Cultural differences

- Country restrictions

- Companies most often begin with modest export involvement.

- A company has four different modes of foreign market entry from which to select:

- Exporting

- Contractual agreements

- $\quad$ Strategic alliances

- $\quad$ Direct foreign investments

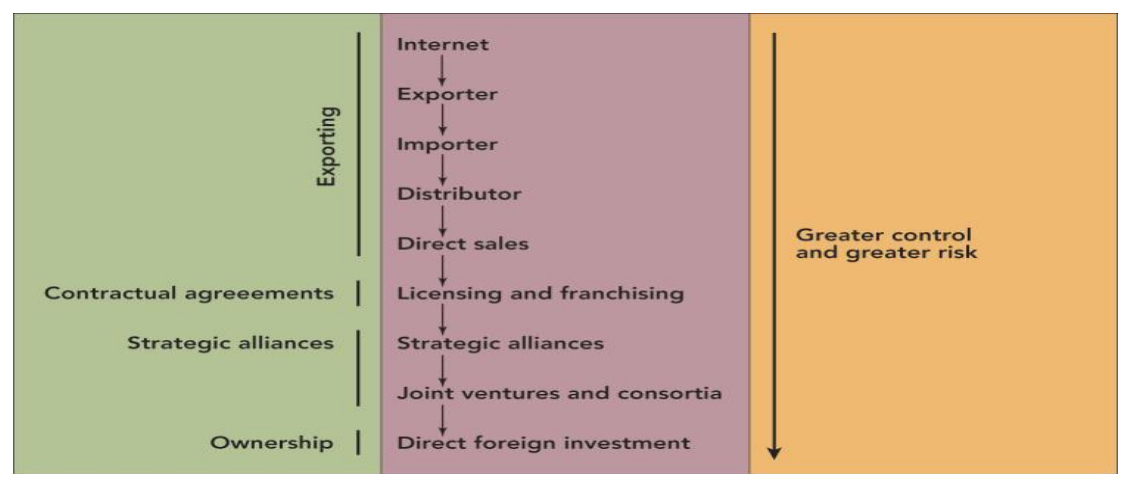

\section{Organizing for Global Competition}

- Locus of decision

- Considerations of where decisions will be made, by whom, and by which method constitutes a major element of organizational strategy.

- Centralized versus decentralized organizations

- An infinite number of organizational patterns for the headquarters activities of multinational firms exist, but most fit into one of three categories:

- Centralized

- Regionalized 
- Decentralized

- No single traditional organizational plan is adequate for today's global enterprise seeking to combine the economies of scale of a global company with the flexibility and marketing knowledge of a local company.

\section{Schematic Marketing Organization Plan Combining Product, Geographic, and Functional Approaches}

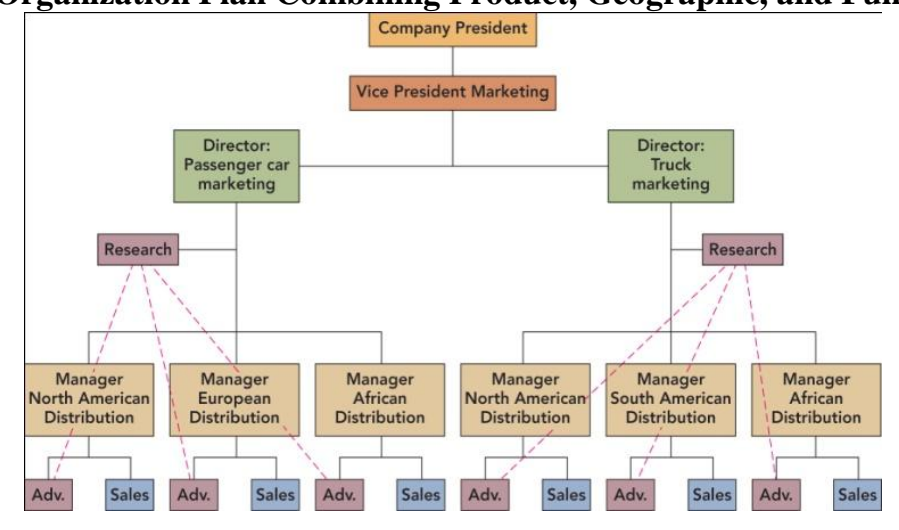

III. Conclusion

Conducting business operations on the contemporary global market means that corporations are constantly faced with a large number of risks, and the implementation of global marketing management should contribute to their comprehension and reduction to acceptable proportions. In other words, improved decision making informational basis enables a business to respond more appropriately to current challenges in global business operations. This is why providing an informational basis should be regarded as the first stage in the conduct of global marketing management, as management decision making is facilitated by the possession of adequate market information. Moreover, identifying gaps in the market in the form of market niches can be crucial, as this is where extra performance is most often achieved in global business. Information global marketing management entails conducting a range of complex activities determined by the business conditions on the contemporary global market, as well as the profile, attitudes and relationships of the chosen market setting. The complexity of the informational basis of the global marketing management is especially manifest in global comparative research, where the research subjects are characteristics of each target market. Marketing research significantly enhances information global marketing management, as they have the features of a process, and is conducted by following a logical sequence of exactly set stages

\section{References}

[1] Churchill, G. A. (1996). Basic Marketing Research. Orlando: The Dryden Press.

[2] Douglas, P. S., \& Craig, C. S. (1983). International Marketing Research.New Jersey: Prentice-Hall.

[3] Jović, M. (2006). International marketing. Belgrade: IntermaNet.

[4] Kotler, P. (2003). Marketing Management. New Jersey: Pearson Education.

[5] Milisavljević, M. (2001). Marketing. Beograd: Savremena administracija.

[6] Salai, S., \& Božidarević, D. (2009). Marketing istraživanje. Subotica: Ekonomski fakultet Subotica.

[7] Vezjak, D. (1991). Međunarodni marketing. Beograd: Savremena administracija.

[8] Zikmund, W. G. (1997). Exploring Marketing Research. Orlando: The Dryden Press.

[9] Joshi, Rakesh Mohan, (2005) International Marketing, Oxford University Press, New Delhi and New York ISBN 019-567123-6

[10] link = Philip Kotler, Philip.; Kevin Lane Keller (2006).Marketing Management, 12th ed.. Pearson Prentice Hall.ISBN 0-13-145757-8.

[11] Clancy, Kevin J.; Peter C. Kriegafsd (2000). Counter intuitive Marketing. The Free Press. ISBN 0-684-85555-0.

[12] Kelle (2002). Strategic Brand Management, 2nd ed.. Prentice Hall. ISBN 0-13-041150-7.

[13] Porter, Michael (1998). Competitive Strategy (revised ed.). The Free Press. ISBN 0-684-84148-7.

[14] Kotler, Philip.; Kevin Lane Keller (2006). Marketing Management, 12th ed.. Pearson Prentice Hall. ISBN 0-13$145757-8$.

[15] Ries, Al; Jack Trout (2000). Positioning: The Battle for Your Mind (20th anniversary ed.). McGraw-Hill. ISBN 007-135916-8.

[16] Porter, Michael (1998). Competitive Advantage (revised ed.).The Free Press. ISBN 0-684-84146-0 